\title{
A INFLUÊNCIA DAS VULNERABILIDADES NO TRATAMENTO DA TUBERCULOSE DROGARRESISTENTE
}

\section{THE INFLUENCE OF VULNERABILITIES ON THE TREATMENT OF DRUG RESISTANT TUBERCULOSIS}

Valdízia Mendes e Silva ${ }^{1}$

Ana Raquel Silva Souza ${ }^{2}$

Jéssica Lins de Oliveira ${ }^{3}$

Alexsandra Antonio da Silva ${ }^{4}$

Aline de Paula Rêgo Graciano Luz ${ }^{5}$

Tânia Maria Ribeiro Monteiro de Figueiredo ${ }^{6}$

RESUMO: Objetivo: Relatar a experiência de graduandas em Enfermagem na condução do Tratamento Diretamente Observado realizado à uma paciente com tuberculose pulmonar drogarresistente, bem como demonstrar a influência das vulnerabilidades durante seu processo terapêutico. Método: Trata-se de um relato de experiência de acadêmicas de enfermagem na realização do tratamento diretamente observado (TDO) à uma paciente com tuberculose pulmonar multidrogarresistente no período entre 11 de junho de 2018 à 14 de maio de 2019 . Resultados: Paciente, 46 anos, sexo feminino, branca, dona de casa, analfabeta, residente do município de Campina Grande-PB. Nega comorbidades e contato prévio com pacientes com tuberculose. Em 2018 apresentou tosse, fadiga, perda de peso, cefaleia, febre vespertina e sudorese noturna, após exames foi diagnosticada com Tuberculose resistente à Rifampicina. Durante o tratamento, a paciente foi exposta a situações de vulnerabilidades de cunho social e programática. Conclusão: O presente relato revelou a urgência de combater o estigma envolvido no adoecimento por TB e demonstrou a efetividade da estratégia do tratamento

\footnotetext{
1 Graduanda em Enfermagem pela Universidade Estadual da Paraíba (UEPB). E-mail: valdiziamendes@hotmail.com.

2 Graduanda em Enfermagem pela Universidade Estadual da Paraíba (UEPB). E-mail: anaraquel.coracao2@gmail.com.

3 Graduanda em Enfermagem pela Universidade Estadual da Paraíba (UEPB). E-mail: jessicalins.05@gmail.com.

${ }_{4}^{4}$ Graduada no Curso de Enfermagem pela Universidade Estadual da Paraíba (UEPB). E-mail: alexsandraansilva@gmail.com.

5 Mestranda em Saúde Pública pela Universidade Estadual da Paraíba (UEPB). E-mail: aline_grac@yahoo.com.br.

${ }^{6}$ Professora Doutora do curso de Pós-Graduação em Saúde Pública da Universidade Estadual da Paraíba. E-mail: taniaribeiro_2@hotmail.com.
} 
diretamente observado na adesão ao tratamento, compreensão do processo de adoecimento e na formação de vínculo com a paciente.

Palavras chave: Tuberculose. Vulnerabilidade Social. Saúde Pública.

ABSTRACT: Objective: To report the experience of nursing students in conducting Directly Observed Treatment Short-course performed on a patient with drug-resistant pulmonary tuberculosis, as well as to demonstrate the influence of vulnerabilities during her therapeutic process. Method: This is an account of the experience of nursing students in carrying out the directly observed treatment Short-couse (DOTS) for a patient with multidrug-resistant pulmonary tuberculosis in the period between June 11, 2018 and May 14, 2019. Results: Patient, 46 years old, female, white, housewife, illiterate, resident of the city of Campina Grande-PB. She denies comorbidities and previous contact with tuberculosis patients. In 2018 she presented with cough, fatigue, weight loss, headache, afternoon fever and night sweats, after exams she was diagnosed with Rifampicin-resistant tuberculosis. During treatment, the patient was exposed to situations of social and programmatic vulnerabilities. Conclusion: The present report revealed the urgency to combat the stigma involved in becoming ill with TB and demonstrated the effectiveness of the treatment strategy directly observed in adhering to treatment, understanding the process of illness and forming a bond with the patient.

Keywords: Tuberculosis. Social vulnerability. Public health. 


\section{INTRODUÇÃO}

A Tuberculose (TB) é uma doença infectocontagiosa causada pelo agente Mycobacterium tuberculosis. A sua capacidade de provocar impactos relevantes na sociedade fortalece os achados que constatam que esta enfermidade é um fenômeno que ultrapassa seu caráter biológico, estando associada às iniquidades econômicas, demográficas e biopsicossociais que estão interligadas com a ocorrência e disseminação da doença (BRASIL, 2019; RODRIGUES et al., 2016; ACOSTA, BASSANESI, 2014; SAN PEDRO, OLIVEIRA, 2013).

A drogarresistência ainda persiste como um grave problema de Saúde Pública mundial. Em 2018, calcula-se que $3,4 \%$ dos casos novos e $18 \%$ dos casos previamente tratados tinham a forma resistente à rifampicina (RR-TB) ou seriam multidrogarresistente (MDR). No mesmo ano, houve aproximadamente 214.000 mortes relacionadas à MDR/RR-TB (WHO, 2019).

No Brasil, ainda em 2018, foram notificados 548 casos de MDR/RR-TB, dos quais apenas 59,3\% (325) obtiveram cura. As regiões do Sudeste $(63,4 \%)$, Centrooeste $(58,8 \%)$ e Nordeste $(58,8 \%)$ apresentaram as maiores taxas de cura entre os casos novos de TB MDR/RR. Dentre os estados do Nordeste, a Paraíba apresentou o menor percentual de cura entre esses casos, sendo 38,5\% (BRASIL, 2019).

A Tuberculose Drogarresistente (TB-DR) acontece quando o agente etiológico não é sensível aos fármacos comumente utilizados no tratamento da TB. Desta maneira, o tratamento deve ser diferenciado, com adição de outros medicamentos, especialmente nos casos de resistência a Rifampicina e Isoniazida, que conferem maior complexidade ao tratamento anti-TB. A ausência de diagnóstico ou retardamento do mesmo favorece a transmissão das cepas resistentes (WHO, 2017; WHO, 2015; BRASIL, 2011).

Tendo em vista as particularidades do tratamento da TB-DR, que o tornam mais complexo em relação ao esquema básico para TB, se faz necessário o uso de estratégias que resultem na melhora da adesão ao tratamento e no 
comprometimento entre profissional, paciente e população para o controle da TB, possibilitando o entendimento do contexto social onde o indivíduo está inserido, bem como sua percepção sobre os fatores relacionados à doença. Diante disso, a Organização Mundial de Saúde (OMS) e Ministério da Saúde (MS) propõem o Tratamento Diretamente Observado (TDO) como método para atingir $85 \%$ de cura e redução do abandono em 5\% (SILVA et al., 2017; BRASIL, 2019; WHO, 2004).

O TDO inclui a observação frequente da ingestão medicamentosa, devendo ser realizada todos os dias da semana. Considera-se TDO quando o acompanhamento da deglutição da medicação ocorre no mínimo três vezes por semana durante todo o tratamento. O TDO é associado na literatura à diminuição de novos casos e transmissão de cepas resistentes aos fármacos anti-TB, bem como o aumento da taxa de sucesso da terapia medicamentosa (BRASIL, 2011; BRASIL, 2019; GETAHUN, 2017).

Além do acompanhamento completo abrangendo os campos biológicos e psicossociais, o TDO é uma ferramenta promotora da construção de vínculo por meio do qual o paciente coloca-se como protagonista da sua evolução terapêutica, viabilizando a melhora do controle da TB. Este vínculo possibilita a detecção precoce das vulnerabilidades que podem atuar como barreiras na adesão ao tratamento, de modo que sejam oferecidos os cuidados necessários para a atenção à saúde dos pacientes (FURLAN, JÚNIOR, MARCON, 2017; FIGUEIREDO et al., 2011; SILVA et al., 2017).

Dentre as vulnerabilidades sociais, pode-se destacar a baixa escolaridade, o estigma e as condições socioeconômicas desfavoráveis, que implicam em baixa renda e situações precárias de moradia. Estes fatores favorecem a suscetibilidade do indivíduo ao adoecimento e desfecho inadequado do tratamento. Deste modo, se faz necessária a ampliação do acompanhamento do paciente a partir do TDO, além de estratégias de proteção social e criação de políticas públicas a fim de minimizar estas vulnerabilidades (SILVA et al., 2017; BRAGA et al., 2012; LUNA et al., 2015).

Dessa forma, o artigo objetiva relatar a experiência de graduandas em enfermagem na condução do Tratamento Diretamente Observado (TDO) realizado à uma paciente com tuberculose pulmonar drogarresistente, bem como demonstrar a influência das vulnerabilidades durante seu processo terapêutico. 


\section{METODOLOGIA}

Trata-se de um relato de experiência construído por meio das vivências de acadêmicas de Enfermagem adquiridas durante a realização do TDO à paciente com tuberculose pulmonar drogarresistente no período de 11 de junho de 2018 a 14 de maio de 2019. As visitas ocorreram no domicílio da paciente, com acompanhamento de três a cinco vezes por semana, que consistia em observação da tomada dos tuberculostáticos, realização de exame físico, aferição dos sinais vitais, além da escuta de enfermagem, a qual viabilizou o estabelecimento de vínculo entre equipefamília-paciente.

O contato com a paciente ocorreu a partir da participação das acadêmicas no projeto de Extensão "Contribuindo para a Efetividade do Tratamento Diretamente Observado como estratégia de controle do tratamento da tuberculose no Serviço Municipal de Referência em Tuberculose no município de Campina Grande/PB - ano X" da Universidade Estadual da Paraíba/Pró-reitoria de Extensão (UEPB/PROEX). estudo é fundamentado na vivência das autoras durante o desenvolvimento de suas atividades como extensionistas, respeitando a confidencialidade e privacidade dos participantes do estudo, assim como é preconizado pela resolução 466/2012 do Conselho Nacional de Saúde, que regulamenta as pesquisas com seres humanos (BRASIL, 2012).

Todas as atividades foram desempenhadas no município de Campina Grande/PB, situado no agreste paraibano, na serra do Boturité/Bacamarte. Possui uma população estimada para 2019 de 409.731 habitantes e densidade demográfica de 648,31 hab/km². O município é organizado em quatro distritos: Campina Grande, Catolé, Galante e São José da Mata. Além disso, é composta por oito Distritos Sanitários que formam a rede municipal de saúde (IBGE, 2010). 


\section{RELATO DE EXPERIÊNCIA}

Paciente (MSS) com 46 anos, sexo feminino, cor branca (autodeclarada), dona de casa, analfabeta, residente do município de Campina Grande/PB. Nega comorbidades e contato prévio com pacientes com tuberculose.

Em período anterior ao diagnóstico para TB, residiam juntamente com a paciente o seu irmão, seus três filhos (dois rapazes com 16, 19 anos e uma moça de 23 anos) e sua mãe (JMS) de 80 anos, idosa esta que possuía sua capacidade de mobilidade prejudicada, quadro crônico de cistocele e incontinência urinária, necessitando de cuidados constantes.

No ano de 2018, a paciente afirma ter apresentado tosse, fadiga, perda de peso, cefaleia, febre vespertina e sudorese noturna. Dias após o início da sintomatologia, dirigiu-se à Unidade de Pronto Atendimento (UPA) onde foi solicitado o raio-X de tórax. A partir dos resultados, as hipóteses diagnósticas eram de tuberculose e pneumonia. Além do exame de imagem, foi solicitado baciloscopia de escarro, o Teste Rápido Molecular (TRM-TB) e a cultura de escarro.

O TRM-TB detectou resistência à Rifampicina, sendo necessária a transferência de paciente para o acompanhamento no Complexo de Doenças Infectocontagiosas Clementino Fraga, onde foi prescrito o esquema medicamentoso da fase de ataque composto por Isoniazida 100mg, Pirazinamida 500mg, Etambutol $400 \mathrm{mg}$ e Estreptomicina injetável. Fazia uso de 9 comprimidos diariamente, sendo três de cada medicamento.

No dia 10 de maio de 2018 deu início ao esquema terapêutico. Após alguns dias de internação, foi transferida para o Serviço Municipal de Referência em Tuberculose em Campina Grande para prosseguimento do tratamento. A partir do dia 11 de junho do mesmo ano, o TDO passou a ser realizado pelas acadêmicas do projeto de extensão "Contribuindo para a Efetividade do Tratamento Diretamente Observado como estratégia de controle do tratamento da tuberculose no Serviço Municipal de Referência em Tuberculose no município de Campina Grande/PB - ano X" (UEPB/PROEX), com supervisão da Professora Coordenadora. 
Durante a primeira visita à paciente, esta mostrava-se tensa, apresentava-se pouco comunicativa, com postura corporal encurvada e sinais de timidez e vergonha. Relatou perda de $3 \mathrm{~kg}$ no processo de adoecimento e dor torácica. Além disso, fazia uso de Estreptomicina injetável, porém queixou-se de falta deste medicamento. Quando questionada sobre os contatos, nos foi informado que havia um mês que sua mãe não residia mais no domicílio, porém não foram revelados os motivos.

Durante a conversa, colhemos informações sobre o histórico da paciente e itinerário diagnóstico, ofertamos informações sobre a TB, formas de prevenção e cuidados, como a etiqueta de tosse (levar o braço à boca ao tossir) e manter o ambiente sempre ventilado e com boa iluminação solar. A filha da paciente nos explicou que a casa tinha apenas uma janela e não possuía abertura para área de serviço ou quintal, de forma que o único acesso ao ambiente externo era a porta da frente.

A situação da casa se tornou uma grande preocupação, pois se configurava como um agente facilitador para a transmissão da TB aos contatos. No ambiente ainda havia colônias de mofo, que impactavam negativamente na saúde dos que ali viviam. A equipe realizava o TDO na sala utilizando máscaras PFF2.

Em um dos dias de realização do TDO, a paciente advertiu a equipe que sua casa estava "alagada" pela chuva. Ela disse envergonhada: "Olhe, me desculpe a situação da casa, aqui em cima tem uma casa e do lado tem um beco. Nesse beco não tem saída de água, mas tem uma rachadura que faz a água vir todinha pra cá, pra minha casa! Toda vez que chove fica desse jeito, olhe! Tudo molhado, as parede tudinho. Quando acordei tava assim, tudo molhado, quarto e tudo." A paciente demonstrava vontade de mudar-se daquele lugar, todavia sua situação financeira não permitia.

Ao longo de seu tratamento, relatou a equipe sobre os problemas que ela enfrentava com seu irmão que, devido a problemas psicológicos e alcoolismo, foi morar com a mesma. "Ele sai, num tem? Passa dias fora bebendo e depois volta pra cá pra eu ajudar porque ele ficou sem dinheiro". Segundo a paciente, devido ao alcoolismo, este já havia sido internado outras vezes em um hospital de referência do município, entretanto, dentre os membros da família, apenas ela forneceu o apoio que seu irmão necessitava. 
Este, também tabagista, não respeitava as condições clínicas dela e a importância de evitar o contato com agentes irritantes, como o tabaco, por exemplo. Nos dias em que estava hospedado em sua casa, não hesitava em acender seus cigarros. Apesar disso, a paciente se sentia sozinha para ajudá-lo e aceitava algumas coisas para evitar maiores complicações.

Somada a essa situação, a paciente enfrentou a questão de que a residência não apresentava boa circulação de ar. Tendo em vista o cenário, sempre que possível a equipe discutia sobre os malefícios de ser um tabagista passivo, bem como as possíveis alternativas para cessar essa situação. Com o passar do tempo, em consequência de muito esforço, a paciente e seus filhos conseguiram que este mesmo irmão criasse o hábito de fumar na varanda ou fora da casa.

Pouco tempo depois, a paciente passou a queixar-se de dores nos pés, os quais permaneciam edemaciados durante todo o dia. Logo foi orientada a realizar caminhadas, fazer compressas quentes e elevação de membros, porém mostrava-se resistente quanto à caminhada, mesmo sendo instruída a caminhar pequenas distâncias na sua rua ou quarteirão. Desta forma, realizou apenas as compressas dentre as orientações fornecidas.

Nos encontros seguintes, a paciente mostrava sinais de confiança na equipe que Ihe acompanhava, se abrindo cada vez mais ao diálogo. Esta afirmou que, ao nos ver de jaleco e máscaras no primeiro contato, se sentiu mal. Ela revelou: "Olhe, quando eu vi vocês tudo de branco, com aquele negoço, jaleco né? O nome? Com as máscaras também, eu tomei um choque. Eu num conhecia vocês né? Mai eu tava doente aí precisava usar. Eu sei que precisa, mai é uma situação chata né?". É válido salientar que profissionais que realizam o TDO à pessoa com TB ou mesmo visita domiciliar devem utilizar a máscara PFF2 ou N-95, enquanto a pessoa com TB permanecer com baciloscopia positiva e em situações de precariedade da ventilação no ambiente domiciliar. Quando em situação de potencial risco de transmissão, mais precisamente durante o primeiro mês de tratamento e também em ambientes de pouca ventilação e luz solar, recomenda-se que o paciente bacilífero utilize máscara cirúrgica ou cubra a boca com o braço ou lenço ao tossir (BRASIL, 2019).

Por diversas vezes ouvimos discursos de desesperança no tratamento, de medo e angústia por ter contraído uma doença séria e com tratamento extenso, que 
nesse caso seria de 12 meses. Há dois anos um de seus filhos havia morrido de linfoma cervical, dessa forma, esta perdeu a confiança em métodos terapêuticos. Dizia: "Meu filho tava doente, a gente via o pescoço dele inchando, criando aqueles caroço, num tem? O médico veio e disse que ele ia ficar bom, que ia tratar dele e tudo. Eu via ele sofrendo, se acabando naquelas quimioterapias. Até que um dia fechou tudo da garganta dele e ele num conseguia respirar mais. Nem com aquele buraco no pescoço, a traqueostomia. Meu fii morreu né? Mas o médico disse que ele ia ficar bom. Eu fiquei mais triste por causa disso sabe?”.

Nesse contexto, paulatinamente, a orientação e o diálogo se tornaram essenciais no processo de tratamento da TB, uma vez que o apoio emocional e ensino quanto ao tratamento reduziu o quadro de medo e desesperança, rompeu o autopreconceito e desfez dúvidas da paciente.

Em junho de 2018, na consulta mensal, a paciente recebeu o resultado da primeira baciloscopia de controle, que apresentou resultado negativo, o que contribuiu para que esta se sentisse melhor, pois não seria mais necessário que a equipe realizasse as visitas utilizando da máscara PFF2. Além disso, relatou que havia dificuldades com a aplicação da Estreptomicina, pois a enfermeira nem sempre estava na Unidade Básica de Saúde (UBS) para injetar o medicamento e, quando a profissional estava presente, faltava o medicamento, caracterizando a vulnerabilidade programática enfrentada pela paciente. Diante de tal situação, ocorreu a substituição da Estreptomicina injetável por 750mg de Levofloxacino via oral.

A vulnerabilidade programática diz respeito à avaliação de programas de controle de doenças, bem como a qualidade da gestão, recursos, comprometimento e monitoramento das instituições de saúde (MUÑOZ SÁNCHEZ; BERTOLOZZI, 2007). No caso de MSS, pode-se observar este tipo de vulnerabilidade principalmente em relação ao atendimento na UBS através da ausência de comprometimento da equipe e recursos insuficientes.

Um dos maiores desafios enfrentados pela equipe no início do tratamento foi a abertura ao diálogo, pois ainda não era possível compreender a completa situação em que a paciente se encontrava e a mesma não conseguia confiar inteiramente no nosso apoio. Várias vezes chegou a perguntar para quê precisava ser acompanhada 
por uma equipe: "Vocês precisam vir sempre? Por que eu não posso me tratar sozinha? Mas eu tomo os remédios certinho e na hora certa!". No entanto, o processo de acolhimento e vínculo estabelece fortes laços entre o profissional e os doentes, possibilitando uma relação baseada na confiança e promovendo a corresponsabilidade da saúde, o que facilita a conquista da cura, pois o paciente torna-se mais confiante e fortalecido (PONCE, 2011). Com o passar do tempo, o vínculo entre as partes envolvidas aumentou, de modo que os membros da família se sentiam à vontade para falar de assuntos interpessoais e situação socioeconômica.

A partir de então, a filha relatou que a paciente já não era mais a cuidadora de sua avó por preconceito de seus irmãos. Assim que a doença foi diagnosticada, a genitora foi levada para morar com um outro filho que não permitia sequer que a paciente a visitasse. Este permaneceu indiferente em relação às explicações fornecidas sobre transmissão da doença e resultados de exames. Além disso, outros irmãos da paciente também pararam de visitá-la, buscando evitar qualquer tipo de contato e apoiando a ideia preconceituosa espalhada na família.

Perante o estigma sofrido por parte de seus parentes, a paciente sentia vergonha de realizar simples atividades. Nos confessou que não se sentia confortável em fazer pequenos passeios ou caminhadas e preferia ficar em casa. Certa vez comentou: "Lugar de doente é em casa né? A pessoa sai de casa os povo fica olhando assim troncho pra pessoa". O único lugar que não deixou de frequentar foi a igreja, lugar no qual sentia-se à vontade e alimentava sua fé na cura da TB.

Durante nossas visitas, comentava sobre seu desejo pelo conhecimento, lembrando que quando era criança sua mãe não incentivou seus estudos, de forma que esta nunca aprendeu a ler e escrever. MSS mostrava vontade de matricular-se na escola onde estuda seu filho mais novo, todavia externava que preferia receber alta do tratamento antes de começar a estudar, mesmo com baciloscopia negativa.

Diversas vezes a paciente apresentava-se cabisbaixa durante o TDO por saudade da mãe. Quando seu irmão permitia que conversassem por chamada de áudio, a genitora manifestava sua vontade de voltar a morar com sua filha e, após muita insistência, este permitiu que a visita ocorresse. 
Com muita alegria, a paciente recebeu sua mãe e pode cuidar dela por poucos dias. Nesse momento, então, afirmou que toda vez que se comunicava com a filha, seu cuidador falava por diversas vezes: "Não sei pra quê falar com aquela tuberculosa! Quer ir lá? Vá simbora. Depois que adoecer eu quero ver!". A genitora dizia que, apesar do seu filho adverti-la sobre a TB e aparentar zelo pela sua saúde, ela não recebia os mesmos bons cuidados na casa do filho quando comparados aos que a filha the oferecia. Segundo relatos da senhora, não havia respeito na nova casa, a idosa era tratada aos gritos, principalmente quando se referia ao seu antigo lar. Depois de uma curta estadia na casa da paciente, voltou à casa onde residia nesse período.

Em agosto de 2018, a partir do resultado da cultura, foi possível observar que a paciente não tinha resistência à Rifampicina. A equipe de referência optou por encerrar a primeira fase do tratamento com os medicamentos que estavam sendo utilizados. Devido à divergência de resultado dos exames, a fase de ataque foi realizada com um esquema de TB resistente. Já na fase de controle, foi utilizado o esquema básico, que iniciou em setembro do mesmo ano, com o início da segunda fase do tratamento, o médico do serviço de referência realizou a mudança do esquema terapêutico para Rifampicina 150mg e Isoniazida $75 \mathrm{mg}$.

Durante o mês de janeiro de 2019, a paciente teve picos hipertensivos e em diversos dias manteve-se com a PA alterada em torno de 140/90mmHg, mostrandose apreensiva durante o TDO. Geralmente normotensa, a equipe desconfiou de um princípio de hipertensão e solicitou o acompanhamento pela Unidade Básica de Saúde. Todavia, se tratava de uma situação muito mais complexa.

A principal renda da família provinha da pensão de viuvez da paciente. A paciente teve seis filhos. O segundo filho veio a óbito por câncer e duas filhas são casadas e não residiam com a mãe. Entre os que residiam na casa, o filho mais velho trabalhava informalmente, não obtendo renda fixa. O mais novo era estudante e não trabalhava. Por último, a filha mais nova estava desempregada, obtendo sua fonte de renda através da revenda de perfumes. O irmão que morava na casa consumia álcool de forma abusiva, demorava dias na rua e a todo momento chegavam cobranças das dívidas que este fazia. No mês em questão, havia muitas contas a serem pagas e um baixo retorno financeiro. A família passava por um difícil 
momento econômico e durante dias enfrentaram dificuldades. A pouca quantidade de alimentos preocupava a paciente, originando os picos hipertensivos.

A paciente relatou que sentia dores gástricas, náuseas e episódios de vômito. A equipe observou a possibilidade do aparecimento dos sintomas terem relação com a má alimentação associada ao uso dos medicamentos. A paciente costumava tomar café da manhã duas horas antes da medicação, como proposto pelo Ministério da Saúde (BRASIL, 2019). Porém, devido às dificuldades financeiras, a paciente passou a alimentar-se apenas com uma xícara de café e poucas bolachas. Durante o resto do dia se alimentava apenas no almoço e jantar com o alimento que lhe era possível, geralmente com baixo teor nutritivo. Toda essa mudança alimentar fez com que MSS tivesse receio de tomar os tuberculostáticos. Uma das dúvidas comuns era: "Esses remédio faz mal? Toda vez que eu tomo me dá uma dor, uma agonia. Faz medo!". A equipe buscou orientar sobre os efeitos adversos possíveis e as formas de evitar e cuidar destes.

Por ser uma mulher reservada, não tínhamos conhecimento sobre a situação econômica da família. Somente após uma sondagem mais profunda e persistente sobre as possíveis causas para o aumento da pressão arterial (PA), foi revelada a real condição financeira. A paciente deixou claro que jamais revelaria a totalidade das circunstâncias para outras pessoas, apenas através do vínculo e confiança conosco ela pôde externar suas preocupações.

Após um mês e meio, a paciente relatou melhorar com relação à situação financeira que a preocupava e, em decorrência disso, a equipe notou que sua PA retornou aos padrões fisiológicos. Mencionou que a melhora das condições financeiras da família deveu-se a um trabalho informal conseguido pelo filho e ao aumento da venda de perfumes. No entanto, a paciente ainda sentia muita falta de sua mãe e preocupava-se bastante com os cuidados que estavam sendo ofertados a ela.

Após muita insistência da genitora, seu filho a levou para morar com a paciente contra a vontade dele, continuando a afirmar que a senhora seria contaminada pela tuberculose. Na ocasião, este manifestou grande fúria diante da escolha da mãe: "Quer ficar com essa tuberculosa? Fique. Não precisa falar comigo 
mais não. É muita ingratidão sua viu!" Além disso, houve agressão verbal contra a paciente.

Apesar de todos os insultos e desavenças geradas na família, a volta de JMS para casa causou um impacto positivo no tratamento e na vida de sua filha. "Agora ela tá mais eu, né? Num tem mais aperreio de saber como é que tão tratando ela por lá. Ela tando pertinho a gente cuida bem direitinho." MSS esboçava mais sorrisos e dialogava mais. Buscava sanar todas as dúvidas, mostrava-se participativa no cuidado consigo mesma e com sua família.

MSS prosseguia o tratamento, sempre tomando os medicamentos no horário proposto. Por vezes deixava de realizar os exames na data marcada por falta de dinheiro para o transporte, situação esta na qual se destaca a vulnerabilidade de cunho social, mas solicitava remarcação para que não deixasse de fazê-los. Próximo ao fim do tratamento, MSS e sua filha nos revelou que o filho mais novo estava se comportando de modo estranho em relação à sua mãe.

MSS desconfiava que o filho, talvez por influência do seu ex-marido, estava tratando-a mal em decorrência de sua doença. "Pra mim isso é o pai dele dizendo coisa de mim. Num sei de porque tô doente, num sei se ele quer dinheiro, ele não me diz nada. É assim comigo, vocês tão vendo. E eu faço tudo que é possível para que ele tenha as coisinhas dele." Até o fim do regime terapêutico o rapaz permaneceu irredutível.

Embora a desmistificação da TB tenha evoluído, ainda é uma doença permeada por tabus e um forte estigma, conforme explicitado no presente relato. Este repercute no meio familiar, modifica vínculos, bem como promove quebras nas relações sociais, constrangimento e redução da autoestima do paciente, de modo que o próprio doente passa a reproduzir discursos embasados nos estigmas sofridos em outras oportunidades (SOUZA, et al., 2015)

No dia 14 de maio de 2019, após o período de um ano, o tratamento foi encerrado e MSS, durante a consulta mensal no Serviço de Referência, recebeu alta por cura, uma vez que seus exames radiológico e bacteriológico tiveram resultados satisfatórios. As extensionistas responsáveis pelo TDO até então realizaram uma última visita à paciente. Neste momento enfatizamos o carinho que nossa equipe construiu durante o tratamento. Também incentivamos a manter uma vida normal, 
com a conquista do sonho de estudar, caminhar e realizar passeios, pequenas coisas que durante os doze meses de tratamento MSS sentia vergonha em decorrência do estigma sofrido devido ao seu diagnóstico.

O estigma enfrentado por MSS e sua repercussão na vida e tratamento da paciente nos marcou. Há uma distância gigante entre falar sobre e vivenciar situações em que o estigma encontra-se tão presente. Não podemos esquecer de mencionar que o TDO foi de grande importância para o desfecho da situação, no incentivo à continuidade do tratamento, melhora da autoestima e confiança na cura.

\section{CONCLUSÃO}

O presente relato revelou a urgência de combater o estigma envolvido no adoecimento por TB, que pode ser realizado por meio de estratégias de educação em saúde que foquem no comprometimento da paciente e família, tendo como alvo o empoderamento individual e coletivo em relação à desconstrução de preconceitos, fortalecimento dos vínculos interpessoais e maior conscientização política na luta pelos direitos à saúde. A estratégia do TDO também precisa ser ampliada, bem como o aprimoramento das políticas públicas de proteção social, com intuito de minimizar o problema da exclusão social e demais vulnerabilidades que possam estar atreladas à situação de adoecimento.

Desta experiência, portanto, foi possível observar que alguns fatores que podem influenciar a adesão ao tratamento e evolução da saúde do paciente, como a condição socioeconômica, o preconceito e o desconhecimento sobre a patologia. Outrossim, corroborou-se que o TDO permitiu que a paciente entendesse seu estado de saúde, como também compreendesse e se comprometesse com o processo de tratamento e cura. Além disso, possibilitou para as graduandas em enfermagem o aperfeiçoamento na assistência à saúde, do mesmo modo que construiu um olhar mais humano e holístico da equipe, visando a valorização e compreensão do processo saúde-doença. 


\section{REFERÊNCIAS BIBLIOGRÁFICAS}

ACOSTA, L. M.; BASSANESI, S. L. The Porto Alegre paradox: social determinants and tuberculosis incidence. Revista Brasileira de Epidemiologia, v. 17, n. 2, p. 88-101, 2014. Disponível em: http://www.scielo.br/scielo.php?script=sci_arttext\&pid=S1415790X2014000600088. Acesso em: 07 de fevereiro de 2020.

BRAGA, J. U. et al. Fatores associados ao abandono do tratamento nos serviços de atenção básica em dois municípios brasileiros, Manaus e Fortaleza, de 2006 a 2008. Caderno de Saúde Coletiva, v. 20, n. 2, p. 225-233, 2012.

BRASIL. Ministério da Saúde. Secretaria de Vigilância em Saúde. Departamento de Vigilância Epidemiológica. Boletim Epidemiológico. Brasília: Ministério da Saúde. v. 50, n. 9, 2019. Disponível em: https://portalarquivos2.saude.gov.br/images/pdf/2019/marco/22/2019-009.pdf. Acesso em: 13 de fevereiro de 2020.

BRASIL. Ministério da Saúde. Secretaria de Vigilância em Saúde. Departamento de Vigilância Epidemiológica. Doenças infecciosas e parasitárias: guia de bolso. Brasília: Ministério da Saúde, $2010 . \quad$ Disponível em: http://bvsms.saude.gov.br/bvs/publicacoes/doencas_infecciosas_parasitaria_guia_bolso.pdf.

Acesso em: 13 de fevereiro de 2020.

BRASIL. Ministério da Saúde. Secretaria de Vigilância em Saúde. Departamento de Vigilância Epidemiológica. Manual de recomendação para o controle da tuberculose no Brasil. Brasília: Ministério da Saúde, 2019. Disponível em: http://bvsms.saude.gov.br/bvs/publicacoes/manual_recomendacoes_controle_tuberculose_bra sil_2_ed.pdf. Acesso em: 13 de fevereiro de 2020.

BRASIL. Ministério da Saúde. Secretaria de Vigilância em Saúde. Departamento de Vigilância Epidemiológica. Tratamento diretamente observado (TDO) da tuberculose na atenção básica: protocolo de enfermagem. Brasília: Ministério da Saúde, 2011. Disponível em: http://bvsms.saude.gov.br/bvs/publicacoes/tratamento_diretamente_observado_tuberculose.pdf. Acesso em: 13 de fevereiro de 2020.

BRASIL. Resolução $n^{\circ} 466$, de 12 de dezembro de 2012. Dispõe sobre diretrizes e normas regulamentadoras de pesquisas envolvendo seres humanos. Diário Oficial [da] República Federativa do Brasil, Brasília, DF, 13 jun. 2013. Disponível em: http://bit.ly/1mTMIS3. Acesso em: 10 mar. 2020.

FIGUEIREDO, T. M. R. M; et al. Desempenho no estabelecimento do vínculo nos serviços de atenção à tuberculose. Revista Rene, Fortaleza, v. 12, p. 1028-1035, 2011. Disponível em: https://www.redalyc.org/pdf/3240/324027978019.pdf. Acesso em: 11 de fevereiro de 2020.

FURLAN, M. C. R.; JÚNIOR, A. G. S.; MARCON, S. S. O vínculo com o profissional de saúde no tratamento de tuberculose: Percepção dos usuários. Revista de Enfermagem do CentroOeste Mineiro, DOI:10.19175/recom.v7i0.1934, 2017.

GENTAHUN, B.; NKOSI, Z. Z. Is directly observed Tuberculosis treatment strategy patientcentered? A mixed method study in Addis Ababa, Ethiopia. PLoS One. Canada, v.1, n.12, p. 828, 2017.2 Disponivel em: https://www.ncbi.nlm.nih.gov/pmc/articles/PMC5538709/pdf/pone.0181205.pdf. Acesso em: 04 de fevereiro de 2020.

IBGE. Instituto Brasileiro de Geografia e Estatística. Acesso em 11 de fevereiro de 2020. 
Disponível em: http://www.ibge.gov.br/home. Acesso em: 05 de fevereiro de 2020.

LUNA, F. D. T. et al. Adherence to Tuberculosis Treatment: Programatic Vulnerability Elements. International Archives of Medicine, v. 8, n. 207, p. 1-8, 2015. Disponível em: https://imed.pub/ojs/index.php/iam/article/view/1239/990. Acesso em: 07 de fevereiro de 2020.

MUÑOZ SÁNCHEZ, A.I., BERTOLOZZI, M.R. Pode o conceito de vulnerabilidade apoiar a construção de conhecimento em Saúde Coletiva? Revista Ciência \& Saúde Coletiva, v. 12, n. 2, p. 319-324, 2007. Disponível em: http://www.scielo.br/pdf/csc/v12n2/a07v12n2.pdf. Acesso em: 12 de março de 2020.

PONCE, M. A. Z; et al. Vínculo profissional/ doente no tratamento da tuberculose: desempenho da atenção básica em município do interior paulista. Revista Latino-Americana de Enfermagem, Ribeirão Preto, v. 19, n. 5, p. 1222-1229, 2011. Disponível em: http://www.scielo.br/scielo.php?script=sci_arttext\&pid=S0104-

$11692011000500021 \&$ Ing=en\&nrm=iso. Acesso em: 26 de janeiro de 2020.

RODRIGUES, I. L. A. et al. Representações sociais da tuberculose por enfermeiros. Revista Brasileira de Enfermagem. Brasília, v. 69, n. 3, p. 532-537, 2016. Disponível em: http://www.scielo.br/pdf/reben/v69n3/0034-7167-reben-69-03-0532.pdf. Acesso em: 07 de fevereiro de 2020.

SAN PEDRO, A.; OLIVEIRA, R. M. Tuberculose e indicadores socioeconômicos: revisão sistemática da literatura. Revista Panamericana de Salud Pública, v. 33, n. 4, p. 294-01, 2013. Disponível em:https://scielosp.org/pdf/rpsp/2013.v33n4/294-301/pt. Acesso em: 12 de fevereiro de 2020.

SILVA, R. D. et al. Patients' perception regarding the influence of individual and social vulnerabilities on the adherence to tuberculosis treatment: a qualitative study. BMC Public Health, DOI 10.1186/s12889-017-4752-3, 2017. Disponivel em: https://www.ncbi.nlm.nih.gov/pmc/articles/PMC5606083/pdf/12889_2017_Article_4752.pdf. Acesso em: 12 de fevereiro de 2020.

WORLD HEALTH ORGANIZATION. Companion handbook to the WHO guidelines for the programmatic management of drug-resistant tuberculosis. Geneva: WHO; 2015. Access on February 11, 2020. Available at: https://www.who.int/tb/publications/pmdt_companionhandbook/en/. Acesso em: 04 de fevereiro de 2020.

WORLD HEALTH ORGANIZATION. Multidrug-Resistant tuberculosis (MDR-TB). Geneva: WHO; 2017. Access on February 11, 2020. Available at: http://www.who.int/tb/challenges/mdr/MDR-RR_TB_factsheet_2017.pdf?ua=1. Acesso em: 04 de fevereiro de 2020.

WORLD HEALTH ORGANIZATION. Global Tuberculosis Report. Geneva: WHO; 2019. Acesso em: 11 de $\quad$ Fevereiro, 2020. Disponível em: https://apps. who.int/iris/bitstream/handle/10665/329368/9789241565714-eng.pdf?ua=1. Acesso em: 04 de fevereiro de 2020. 